\title{
HUBUNGAN PENGETAHUAN TENTANG PEMERIKSAAN KEHAMILAN DENGAN KEPATUHAN KUNJUNGAN ANTENATAL CARE DI PUSKESMAS WAJOK HULU KECAMATAN SIANTAN KABUPATEN MEMPAWAH TAHUN 2019
}

\author{
Alexander $^{1}$, Nurul Hudayanti ${ }^{2}$
}

Akademi Kebidanan Panca Bhakti Pontianak

Email korespondensi: akbidpbpontianak@gmail.com

\begin{abstract}
Abstrak
Kehamilan merupakan proses yang normal dan alamiah. Perubahan - perubahan yang terjadi pada wanita selama kehamilan normal adalah bersifat fisiologis, bukan patologis, oleh karenanya asuhan yang diberikan adalah asuhan yang meminimalkan intervensi. Masa kehamilan dimulai dari konsepsi sampai lahirnya janin, lamanya hamil normal adalah 280 hari (40 minggu atau 9 bulan 7 hari) dihitung dari hari pertama haid terakhir.Penelitian ini bertujuan untuk mengetahui apakah ada hubungan pengetahuan ibu tentang pemeriksaan kehamilan dengan kepatuhan kunjungan antenatal care di Puskesmas Wajok Hulu. Desain penelitian ini menggunakan metode deskriptif korelasi dengan pendekatan cross sectional dan sampel yang digunakan 42 orang sampel. Hasil penelitian sebagian besar dari responden yaitu 26 responden $(62 \%)$ berpengetahuan kurang dan hampir seluruh dari responden yaitu 34 responden $(81 \%)$ tidak patuh dalam melakukan kunjungan kehamilan sesuai standar. Kesimpulan penelitian ini tidak ada hubungan antara Pengetahuan Pemeriksaan Kehamilan dengan Kepatuhan Kunjungan Antenatal Care di Puskesmas Wajok Hulu Kabupaten Mempawah Tahun 2019 dengan hasil X² hitung $(1,9)<\mathrm{X}^{2}$ tabel $(5,991)$
\end{abstract}

Kata Kunci: Pengetahuan, Pemeriksaan Kehamilan, Kepatuhan ANC

\begin{abstract}
Pregnancy is a normal and natural process. The changes that occur in women during normal pregnancy are physiological, not pathological, therefore the care provided is care that minimizes intervention. The gestation period starts from conception to the birth of the fetus, the length of normal pregnancy is 280 days (40 weeks or 9 months 7 days) calculated from the first day of the last menstruation. This study aims to determine whether there is a relationship between maternal knowledge about antenatal care and compliance with antenatal care visits at Wajok Hulu Community Health Center. This research design uses descriptive correlation method with cross sectional approach and the sample used is 42 samples. The results of the study, most of the respondents, namely 26 respondents $(62 \%)$ lacked knowledge and almost all of the respondents, namely 34 respondents $(81 \%)$, did not comply with standard pregnancy visits. The conclusion of this study is that there is no relationship between Knowledge of Pregnancy Examination and Compliance with Antenatal Care Visits at Wajok Hulu Public Health Center in Mempawah Regency in 2019 with the results of $X^{2}$ count (1.9) < $X^{2}$ table $(5.991)$
\end{abstract}

Keywords: Knowledge, Antenatal Care, ANC Compliance

\section{Pendahuluan}

Antenatal care merupakan komponen pelayanan kesehatan ibu hamil terpenting untuk menurunkan angka kematian ibu dan bayi. Tingginya angka kematian ibu dan bayi antara lain disebabkan rendahnya tingkat pengetahuan ibu dan frekuensi pemeriksaan antenatal care yang tidak teratur. Keteraturan antenatal care dapat ditunjukkan melalui frekuensi kunjungan, ternyata hal ini menjadi masalah karena tidak semua ibu hamil memeriksakan kehamilannya secara rutin sehingga kelainan yang timbul

\footnotetext{
${ }^{1}$ Dosen Akademi Kebidanan Panca Bhakti Pontianak

${ }^{2}$ Mahasiswa Akademi Kebidanan Panca Bhakti Pontianak
} 
dalam kehamilan tidak dapat terdeteksi sedini mungkin (Sarwono, 2010).

Antenatal care merupakan suatu pelayanan yang diberikan oleh bidan kepada wanita selama hamil. Misalnya dengan pemantauan kesehatan secara fisik, psikologis, termasuk pertumbuhan dan perkembangan janin serta mempersiapkan proses persalinan dan kelahiran supaya ibu siap menghadapi peran baru sebagai orang tua (Wagiyo \& Putrono, 2016).

Tingkat pengetahuan mempengaruhi sikap kesehatan, yaitu hal-hal yang berkaitan dengan tindakan atau kegiatan seorang dalam memilih dan meningkatkan kesehatan. Termasuk juga tindakan untuk mencegah penyakit, memilih makanan, sanitasi dan pengetahuan tentang keteraturan antenatal care penting untuk diketahui oleh ibu hamil agar segera mungkin menentukan sikap (Notoatmodjo, 2012).

Kepatuhan (adherence) adalah suatu bentuk perilaku yang timbul akibat adanya interaksi antara petugas kesehatan dan pasien sehingga pasien mengerti rencana dan segala konsekwensinya dan menyetujui rencana tersebut serta melaksanakannya (Kemenkes RI, 2011).

Kebijakan yang berlaku di Indonesia untuk kunjungan antenatal care minimal 4 kali selama kehamilan yaitu minimal I kali pada trimester satu, minimal I kali pada trimester II, dan minimal 2 kali pada trimester III. Antenatal care secara teratur pada ibu hamil diharapkan mampu mendeteksi dini dan menangani komplikasi yang sering terjadi pada ibu hamil, sehingga hal ini penting untuk menjamin bahwa proses alamiah dari kehamilannya berjalan dengan normal (WHO, 2016).

Menurut data Riskesdes, menunjukkan ibu hamil di Indonesia pada perempuan umur 10 - 54 tahun sebanyak $(95,2 \%)$, dan yang sudah melakukan pemeriksaan kehamilan K1 dan frekuensi kehamilannya minimal 4 kali selama masa kehamilannya adalah $(81,3 \%)$. Sedangkan yang sudah melakukan pemeriksaan kehamilan K4 adalah $(70,0 \%)$.

Jika dilihat berdasarkan kasus kematian maternal yang terjadi pada tahun 2017 di Provinsi Kalimantan Barat, tercatat sebanyak 98 kasus kematian ibu. Sehingga jika dihitung angka kematian ibu maternal dengan jumlah kelahiran hidup sebanyak 86,572, maka kematian ibu maternal di Provinsi Kalimantan Barat pada tahun 2016 adalah sebesar 113 per 100.000 kelahiran hidup. Kasus kematian ibu maternal ada di Kabupaten Sanggau, yaitu sebesar 15 ibu maternal dan terkecil ada di Kabupaten Kapuas Hulu, yaitu sebesar 2 ibu maternal (Profil Kesehatan Provinsi Kalimantan Barat Tahun 2017).

Kunjungan K4 Kabupaten Mempawah Tahun 2017 adalah sebesar 81,91\%, tahun 2016 sebesar $83,74 \%$. Artinya mengalami penurunan dibandingkan dengan tahun-tahun sebelumnya. Target cakupan kunjungan K4 adalah sebesar 95\% artinya cakupan tahun 2017 tidak mencapai target. Sementara upaya yang dilakukan untuk meningkatkan cakupan serta pelayanan yang berkualitas dilakukan pendistribusian register kohort ibu dan format laporan lainnya termasuk stiker perencanaan 
kehamilan dan penanganan komplikasi (P4K) bagi ibu hamil sehingga ibu hamil dapat terpantau dan terdata (Profil Kesehatan Kabupaten Mempawah Tahun 2017).

Berdasarkan data diatas dari bulan Januari sampai bulan Desember 2018, ibu hamil yang melakukan kunjungan antenatal care sebanyak 817 orang. Dari 817 orang ibu hamil, 426 orang yang kunjungan K1 dan 390 orang ibu hamil yang kunjungan K4. Dilihat dari kohort ibu, yang melakukan kunjungan antenatal care secara rutin adalah ibu yang baru pertama kali hamil. Sedangkan ibu yang sudah memiliki anak sebelumnya, lebih jarang melakukan kunjungan antenatal care dikarenakan ibu merasa tidak ada keluhan pada kehamilannya.

\section{Metode}

Pada penelitian ini menggunakan metode deskriptif korelasi dengan pendekatan secara cross sectional. Sampel dalam penelitian ini sebanyak 42 ibu hamil yang melakukan pemeriksaan Antenatal Care di Puskesmas Wajok Hulu. Pengumpulan data menggunakan kuesioner, kemudian diolah dan dianalisis menggunakan analisis univariat serta analisis bivariat menggunakan uji chi square.

\section{Hasil dan Pembahasan}

Tabel 1 Distribusi Frekuensi Pengetahuan Ibu Tentang Pemeriksaan Kehamilan di Puskesmas Wajok Hulu Kabupaten Mempawah Tahun 2019

\begin{tabular}{lllcl}
\hline & Pengetahuan Responden & $\mathrm{N}$ & \multicolumn{2}{c}{$\%$} \\
\hline Kurang & & 26 & 62 \\
Cukup & & 12 & 28,5 & \\
Baik & & 4 & 9,5 & \\
\hline Sebagian besar dari responden yaitu 26 & $(9,5 \%)$ & berpengetahuan & baik & tentang \\
responden (62\%) berpengetahuan kurang dan & pemeriksaan kehamilan & &
\end{tabular}
sangat sedikit dari responden yaitu 4 responden

Tabel 2 Distribusi Frekuensi Sikap Kepatuhan Kunjungan Antenatal care di Puskesmas Wajok Hulu Kecamatan Siantan Kabupaten Mempawah Tahun 2019

\begin{tabular}{lccc}
\hline & Kepatuhan & N & $\%$ \\
\hline Tidak Patuh & 34 & 81 \\
Patuh & 8 & 19 \\
\hline
\end{tabular}

Hampir seluruh responden yaitu 34 responden kehamilan sesuai standar. $(81 \%)$ tidak patuh dalam melakukan kunjungan

Tabel 3 Hubungan Antara Pengetahuan Dengan Sikap Dalam Memberikan Imunisasi Campak Pada Ibu Yang Mempunyai Bayi Usia > 9-11 Bulan Di Puskesmas Sungai Raya DalamTahun 2019

\begin{tabular}{|c|c|c|c|c|c|c|c|}
\hline \multirow{3}{*}{ Pengetahuan } & \multicolumn{4}{|c|}{ Kepatuhan } & \multirow{3}{*}{ Total } & \multirow{3}{*}{$\begin{array}{c}\mathrm{P} . \\
\text { Value }\end{array}$} & \multirow{3}{*}{$\alpha$} \\
\hline & \multicolumn{2}{|c|}{ Tidak Patuh } & \multicolumn{2}{|c|}{ Patuh } & & & \\
\hline & $\sum$ & $\%$ & $\sum$ & $\%$ & & & \\
\hline Kurang & 21 & 61,7 & 5 & 62,5 & 26 & & \\
\hline Cukup & 10 & 29,4 & 2 & 25 & 12 & 0,573 & 0,05 \\
\hline Baik & 3 & 8,9 & 1 & 12,5 & 4 & & \\
\hline
\end{tabular}


Hasil uji statistic didapat nilai $\mathrm{p}$ value $=$ $0,573>\alpha=0,05$ maka dapat di simpulkan tidak ada hubungan yang bermakna antara pengetahuan ibu hamil tentang pemeriksaan kehamilan dengan kepatuhan kunjungan antenatal care.

\section{Pengetahuan Responden}

Pengetahuan adalah hasil penginderaan manusia, atau hasil tahu seseorang terhadap objek melalui indera yang dimiliki (mata, hidung, telinga, dan sebagainya (Notoatmodjo, 2010).

Antenatal care merupakan komponen pelayanan kesehatan ibu hamil terpenting untuk menurunkan angka kematian ibu dan bayi. Tingginya angka kematian ibu dan bayi antara lain disebabkan rendahnya tingkat pengetahuan ibu dan frekuensi pemeriksaan antenatal care yang tidak teratur. Keteraturan antenatal care dapat ditunjukkan melalui frekuensi kunjungan, ternyata hal ini menjadi masalah karena tidak semua ibu hamil memeriksakan kehamilannya secara rutin sehingga kelainan yang timbul dalam kehamilan tidak dapat terdeteksi sedini mungkin (Prawirohardjo, 2010).

Antenatal care merupakan suatu pelayanan yang diberikan oleh bidan kepada wanita selama hamil. Misalnya dengan pemantauan kesehatan secara fisik, psikologis, termasuk pertumbuhan dan perkembangan janin serta mempersiapkan proses persalinan dan kelahiran supaya ibu siap menghadapi peran baru sebagai orang tua (Wagiyo \& Putrono, 2016).

Menurut peneliti kurangnya pengetahuan ibu hamil tentang kunjungan antenatal care salah satunya disebabkan oleh faktor pendidikan yang ibu tempuh karena sebagian dari responden hanya menempuh pendidikan Sekolah Dasar dan Sekolah Menengah Pertama selain itu rasa ingin tahu yang dimiliki ibu juga kurang karena masih banyak responden yang tidak mengikuti kelas ibu bahkan masih banyak ibu hamil yang tidak melakukan kunjungan antenatal care secara teratur. Padahal pengetahuan tidak hanya dipandang dari jenjang pendidikan saja namun dari media massa pun ibu sebenarnya mudah untuk mendapatkan informasi. Pengetahuan yang kurang juga bisa disebabkan karena kurang informasi yang diberikan secara langsung oleh tenaga kesehatan atau yang diperoleh dari media massa dan ketika mendapatkan buku KIA biasanya ibu hamil hanya membawa pulang dan tidak di baca padahal bidan ada menganjurkan untuk membaca buku KIA dimana didalam buku ibu hamil ada dianjurkan untuk melakukan antenatal care secara teratur.

\section{Kepatuhan Responden}

Kepatuhan (adherence) adalah suatu bentuk perilaku yang timbul akibat adanya interaksi antara petugas kesehatan dan pasien sehingga pasien mengerti rencana dan segala konsekwensinya dan menyetujui rencana tersebut serta melaksanakannya (Kemenkes RI, 2011).

Kepatuhan kunjungan kehamilan diperoleh melalui perhitungan kunjungan kehamilan. Ibu hamil dikategorikan patuh apabila ibu hamil melakukan kunjungan kehamilan minimal 1 kali pada trimester I, 1 kali pada trimester II dan 
2 kali pada trimester III sebaliknya ibu hamil dikatakan tidak patuh apabila ibu tidak melakukan kunjungan kehamilan minimal 1 kali pada trimester I (0-12 minggu), 1 kali pada trimester II (13-28 minggu) dan 2 kali pada trimester III (29-36 minggu).

Menurut penelitian berdasarkan hasil observasi terhadap kepatuhan kunjungan kehamilan pada buku KIA responden diketahui bahwa hampir seluruh dari responden yaitu 34 responden $(81 \%)$ tidak patuh dalam melakukan kunjungan antenatal care sesuai standar, dan sangat sedikit dari responden yaitu 8 responden (19\%) yang patuh dalam kunjungan antenatal care sesuai standar.

Karena hampir seluruh responden tidak melakukan kunjungan antenatal care sebanyak 4 kali, hal ini disebabkan beberapa faktor misalnya pengetahuan ibu yang kurang tentang manfaat kunjungan antenatal care selain itu kurangnya partisipasi ibu dalam kunjungan antenatal care karena biasanya ibu menganggap bahwa kehamilan sekarang tidak ada perbedaan dengan kehamilan yang lalu sehingga ibu tidak memiliki kemauan untuk melakukan kunjungan antenatal care.

\section{Hubungan Pengetahuan Ibu Hamil Tentang Pemeriksaan Kehamilan Dengan Kepatuhan \\ Kunjungan Antenatal Care}

Menurut Pantikawati \& Saryono (2010) kepatuhan melakukan pemeriksaan antenatal care didefinisikan perilaku ibu hamil yang mentaati semua anjuran oleh petugas kesehatan dalam melakukan pemeriksaan antenatal care. Kepatuhan kunjungan kehamilan diperoleh melalui perhitungan kunjungan kehamilan. Ibu hamil dikategorikan patuh apabila ibu hamil melakukan kunjungan kehamilan minimal 1 kali pada trimester I, 1 kali pada trimester II dan 2 kali pada trimester III sebaliknya ibu hamil dikatakan tidak patuh apabila ibu tidak melakukan kunjungan kehamilan minimal 1 kali pada trimester I (0-12 minggu), 1 kali pada trimester II (13-28 minggu) dan 2 kali pada trimester III (29-36 minggu).

Didalam penelitian ini diperoleh bahwa tidak ada hubungan antara pengetahuan tentang Pemeriksaan Kehamilan Dengan Kepatuhan Kunjungan antenatal care karena pengetahuan ibu yang masih kurang tentang kunjungan antenatal care dilihat dari masih banyaknya responden yang menjawab salah. Hal ini bisa dikarenakan pengetahuan bisa mempengaruhi prilaku ibu hamil, termasuk dalam hal melakukan kunjungan antenatal care dimana ibu hamil dengan pengetahuan yang kurang maka akan menyebabkan ibu hamil juga bisa tidak patuh melakukan kunjungan antenatal care

Sebaiknya tenaga kesehatan Puskesmas Wajok Hulu memberikan penyuluhan atau konseling kepada ibu hamil tentang pentingnya pemeriksaan kehamilan dan kepatuhan kunjungan antenatal care agar ibu hamil dapat menerima informasi dengan baik sehingga dapat memberikan motivasi untuk ibu dalam melakukan pemeriksaan kehamilan dan kunjungan antenatal care. Apabila ibu mendapatkan informasi yang jelas maka pengetahuan ibu akan bertambah, pengetahuan akan berpengaruh dalam membentuk tindakan, 
sikap dan keterampilan seseorang. Misalnya ibu hamil bisa mengenali $4 \mathrm{~T}$ (terlalu tua, terlalu muda, terlalu dekat dan terlalu jauh). Selain itu kunjungan antenatal care tidak hanya dipengaruhi oleh pengetahuan ibu hamil, ada faktor - faktor lain yang bisa mempengaruhi seperti umur, pendidikan, pekerjaan dan paritas. Hal ini sesuai dengan teori (Munawaroh, 2017).

\section{Kesimpulan}

Tidak ada hubungan yang bermakna antara pengetahuan ibu hamil tentang pemeriksaan kehamilan dengan kepatuhan kunjungan antenatal care.

\section{Daftar Pustaka}

Asrinah. 2010. Asuhan Kebidanan Masa Kehamilan. Yogyakarta: Graha Ilmu

Dewi, Ratna. 2012 Asuhan Kebidanan Pada Ibu Hamil Normal dan Patologi. Yogyakarta: Nuha Medika

Fauziah, Arfoh \& Sudarti. 2014. Hubungan Tingkat Pengetahuan Ibu Hami Tentang ANC dengan Frekuensi Kunjungan ANC di BPS Fajar Samiati, Yogoyudan, Wates, Kulon Progo, Yogyakarta. Jurnal Medika Respati. Volume: 9. No.2 April 2014. Website:https://ojs.dinamikakesehatan.unis m.ac.id

Indrayani. 2011. Buku Ajar Asuhan Kebidanan. Jakarta Timur: CV. Trans Info Media

Kuswati, Ina. 2014. Asuhan Kehamilan. Yogyakarta: Pustaka Pelajar

Lockhart, Anita, Saputra, Lyndon. 2014. Asuhan Kebidanan Kehamilan Fisiologis \& Patologis. Tanggerang Selatan: Binarupa Aksara
Marni. 2011. Asuhan Kebidanan Pada Masa Antenatal. Yogyakarta: Pustaka Pelajar

Munawaroh, Ismiyatun. 2017. Gambaran Kepatuhan Ibu Hamil Dalam Antenatal Care (ANC) di Wilayah Kerja Puskesmas Kokap I. Website: repository.unjaya.ac.id

Notoatmodjo, Soekidjo. 2010. Promosi Kesehatan Teori dan Aplikasi. Jakarta: Rineka Cipta.

.2012. Metodelogi Penelitian Kesehatan. Jakarta: Rineka Cipta

Oktaviani, Lina. 2018. Kunjungan Antenatal Care (ANC) ditinjau dari Tingkat Pengetahuan Ibu Hamil Tentang Tanda Bahaya Kehamilan. Baturaja. Junal Aisyah, Jurnal Ilmu Kesehatan. 2018. Vol. 3, No.1 Juni $2018 . \quad$ Website: https://ejournal.stikesaisyah.ac.id

Purwanti, Hardiani. 2012. Motivasi dan Kepatuhan Kunjungan Antenatal Care (ANC) Pada Ibu Hamil Trimester III. Jurnal Ilmu Keperawatan. 2012. Volume. 3, No.2 Juli 2012. Website: https://media.neliti.com

Prawirohardjo, Sarwono. 2010. Ilmu Kandungan. Jakarta: PT. Bina Pustaka Sarwono Prawirohardjo

Pantikawati, Ika, \& Saryono. 2010. Asuhan Kebidanan 1 (kehamilan). Yogyakarta: Nuha Medika

Putrono, Wagiyo. 2016. Asuhan Keperawatan Antenatal, Intranatal \& Bayi Baru Lahir Fisiologis dan Patologis. Yogyakarta: CV.Andi

Profil Dinas Kesehatan Kabupaten Mempawah, 2015. Cakupan K1 dan K4 tahun 2014 s/d 2017. Website: www.depkes.go.id

Profil Kesehatan Provinsi Kalimantan Barat, 2017. Kasus Kematian Ibu Maternal di Provinsi Kalimantan Barat. Website: www.depkes.go.id 
Putri, Amega , \& Asnindari, Nurdia , Lutfi 2016. Hubungan Pengetahuan dan Sikap Ibu Hamil Tentang Antenatal Care dengan Kunjungan Frekuensi Kunjungan Antenatal Care di Puskesmas Umbulharjo 1 Yogyakarta. Jurnal Penelitian, Fakultas Kesehatan Masyarakat. Website: https://repository.unhas.ac.id

Romauli, Suryati. 2011. Asuhan Kebidanan 1. Yogyakarta: Nuha Medika

Reskiani, Nurul Miftah, balqis. 2014 Hubungan Perilaku Ibu Hamil Dengan Pemanfaatan Pelayanan Antenatal Care di Puskesmas Antang Tahun 2014. Yogyakarta. Jurnal Penelitian, Universitas Aisyiyah. Website: http://lib.unisayogya.ac.id

Sofiana, Desi. 2015. Gambaran Tingkat Kepatuhan Ibu Dalam Pemberian Tablet Zinc Pada Balita Diare. Banyumas. Website: repository.ump.ac.id

Sulistyawati, Ari. 2009. Asuhan Kebidanan Pada Masa Kehamilan: Salemba Medika

Susila, Suyanto. 2014. Metodologi Penelitian Cross Sectional. Klaten Selatan: Bossscript

Setiawan, Ari. 2011. Metodologi Penelitian Kebidanan. Yogyakarta: Nuha Medika
Sari, Anggrita. 2015. Asuhan Kebidanan Pada Kehamilan. Bogor: In Media

Sugiyono. 2013. Metodelogi Penelitian Kuantitatif, Kualitatif dan R\&D. Bandung : Alfabeta

2017. Metodelogi Penelitian Kuantitatif, Kualitatif dan R\&D. Bandung : Alfabeta.

WHO. 2016. WHO Recommendations On Antenatal Care For Positive Pregnancy Eksperience. Jurnal WHO. Website: http://apps.who.int/iris/bitsream/10665/250 796/1/9789241549912-eng.pdf?ua=1

Waryana. 2016. Promosi Kesehatan, Penyuluhan dan Pemberdayaan Masyarakat. Yogyakarta : Nuha Medika

Wulandatika, Darmayanti. 2013. Faktor Faktor yang Berhubungan dengan Kepatuhan Ibu Dalam Melakukan Kunjungan Antenatal Care di Wilayah Kerja Puskesmas Gabut Kabupaten Banjar Kalimantan Selatan. Jurnal Ilmu Keperawatan dan Kebidanan; Volume 8. No.2 (2017) 8-18. Website: https://journals.stikim.ac.id 